[2] Esser N, Legrand-Poels S, Piette J, Scheen AJ, Paquot N. Inflammation as a link between obesity, metabolic syndrome and type 2 diabetes. Diabetes Res Clin Pract 2014;105:141-50.

[3] Otero M, Lago R, Gomez R, et al. Changes in plasma levels of fat-derived hormones adiponectin, leptin, resistin and visfatin in patients with rheumatoid arthritis. Ann Rheum Dis 2006;65:1198-201.

[4] Schaffler A, Ehling A, Neumann E, et al. Adipocytokines in synovial fluid. JAMA 2003;290:1709-10.

[5] Frommer KW, Zimmermann B, Meier FM, et al. Adiponectin-mediated changes in effector cells involved in the pathophysiology of rheumatoid arthritis. Arthritis Rheum 2010;62:2886-99.

[6] Kitahara K, Kusunoki N, Kakiuchi T, Suguro T, Kawai S. Adiponectin stimulates IL-8 production by rheumatoid synovial fibroblasts. Biochem Biophys Res Commun 2009;378:218-23.

A

$$
\text { IL-6 in PBMCs }
$$
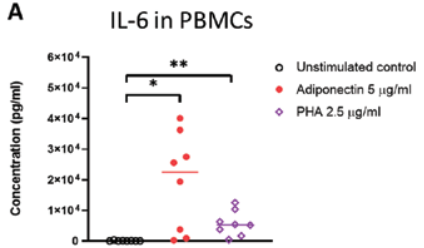

B

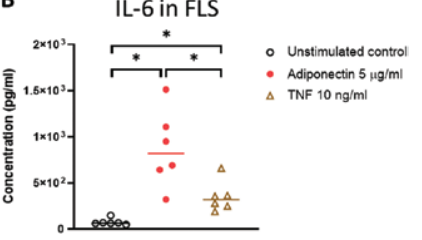

Figure 2. Adiponectin induces the production of IL-6 PBMCs (A) FLS (B) measured using ELISA.

Disclosure of Interests: Yuan Zhang: None declared, Jonathan Aldridge: None declared, Georgios K. Vasileiadis: None declared, Anna-Carin Lundell: None declared, Anna Rudin Consultant of: Astra/Zeneca, Cristina Maglio: None declared DOI: 10.1136/annrheumdis-2020-eular.3215

\section{AB0111 THE COMPARISON OF SYNDECAN-4 LEVEL IN SERA, SYNOVIAL FLUID AND SYNOVIUM OF RHEUMATOID ARTHRITIS AND OSTEOARTHRITIS}

\section{J. Zhao ${ }^{1}$, X. Ye ${ }^{2}$, Z. Zhang ${ }^{2} .{ }^{1}$ Peking University First Hospital Rheumatology} and Immunology Department, Beijing, China; ${ }^{2}$ Peking University First Hospital Rheumatology and Immunology Department, Beijing, China

Background: Syndecan-4, one of the members of heparan sulphate proteoglycans (HSPGs), has been shown to be involved in regulating inflammatory responses, angiogenesis, and cell migration. Its role has been proved in animal arthritis models, however not clearly elucidated in rheumatoid arthritis (RA) patients

Objectives: To investigate the role of Syndecan-4 in the pathogenesis of RA, by detecting Syndecan-4 expression in the serum, synovial fluid and synovium of RA patients and comparing with osteoarthritis $(\mathrm{OA})$ patients

Methods: The concentrations of syndecan-4 in sera and synovial fluid of RA and osteoarthritis (OA) patients were detected by ELISA. The expression of syndecan-4 in synovium of RA and OA patients was detected by immunohistochemistry. In another cohort of 60 RA patients, the association analysis was performed. All the RA patients were with disease duration more than 6 months and with DAS28-CRP>3.2 although after csDMARDs (including MTX and/or leflunomide) treatment for more than 3 months. The RA patients were treated with tumour necrosis factor a (TNFa) inhibitor (TNFi) and MTX 10mg per week for 12 weeks. The correlations between sera Syndecan- 4 and disease activity of RA as well as therapeutic response to TNFi were analyzed.

Results: The serum Syndedcan-4 level of RA patients [637.1 (483.6-1069.6) pg/ $\mathrm{mL}$ ] was significantly higher than that of OA patients [345.0 (287.9-421.1) pg/ $\mathrm{mL}]$ and healthy controls $[195.6(165.0-225.2) \mathrm{pg} / \mathrm{mL}](\mathrm{P}<0.001, \mathrm{P}<0.001$, respectively). The serum concentration of Syndecan-4 is also higher in OA patients than that in healthy controls $(\mathrm{P}<0.001)$. It was also higher in RF-positive RA patients than in RF-negative ones [603.0 (100.0-8879.1) pg/mL vs 460.3 (178.7-2468.9) $\mathrm{pg} / \mathrm{mL},(p=0.026)]$. The Syndedcan-4 level in synovial fluid and synovia were comparable between RA and OA patients. No correlation was found between serum Syndedcan-4 and disease activity of RA. TNFi treatment did not change the serum Syndecan-4 level significantly. The baseline serum Syndecan-4 did not show predictive value for TNFi response.
Conclusion: Syndecan-4 can be expressed in the synovia of RA and OA patients. The serum Syndecan-4 is higher in RA patients than in OA patients and healthy controls, and significantly higher in sero-positive RA patients than in sero-negative ones. Syndecan-4 may participate in the pathogenesis of RA

References:

[1] Leonova El, Galzitskaya OV. Role of Syndecans in Lipid Metabolism and Human Diseases. Adv Exp Med Biol, 2015, 855: 241-58.

[2] Xie J, Wang J, Li R, Dai Q, Yong Y, Zong B, et al. Syndecan-4 over-expression preserves cardiac function in a rat model of myocardial infarction. $\mathrm{J} \mathrm{Mol}$ Cell Cardiol 2012; 53: 250-8.

[3] Strand ME, Aronsen JM, Braathen B, Sjaastad I, Kvaløy H, Tønnessen T, et al. Shedding of syndecan-4 promotes immune cell recruitment and mitigates cardiac dysfunction after lipopolysaccharide challenge in mice. J Mol Cell Cardiol. 2015;88:133-44.

[4] Endo T, Ito K, Morimoto J, Kanayama M, Ota D, Ikesue M, et al. Syndecan 4 Regulation of the Development of Autoimmune Arthritis in Mice by Modulating B Cell Migration and Germinal Center Formation. Arthritis Rheumatol. 2015; 67:2512-22.

Disclosure of Interests: None declared

DOI: 10.1136/annrheumdis-2020-eular.1587

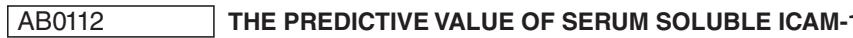 AND CXCL13 IN THE THERAPEUTIC RESPONSE IN RHEUMATOID ARTHRITIS PATIENTS}

J. Zhao ${ }^{1}$, X. Ye ${ }^{1}$, Z. Zhang ${ }^{1} .{ }^{1}$ Peking University First Hospital Rheumatology and Immunology Department, Beijing, China

Background: Tumor Necrosis Factor-a (TNFa) inhibitors (TNFi) have greatly improved the prognosis of RA, but not all these patients respond well to TNFi. So far there has been no definite biomarker to predict the response to TNFi yet. Objectives: The aim of current study was to explore the predictive value of sICAM-1 and CXCL13 on the response to TNFa receptor fusion protein in RA patients who have poor response to conventional synthetic disease-modifying anti-rheumatic drugs (csDMARDs).

Methods: 60 RA patients with disease duration more than 6 months and at least low disease activity definded by DAS28-CRP $>3.2$ although after csDMARDs treatment for more than 3 months were included. They were furthe treated with TNFa receptor Fc fusion protein and MTX $10 \mathrm{mg}$ per week for 12 weeks. Soluble ICAM-1 (sICAM-1) and CXCL13 concentrations in sera from 60 RA patients and 20 healthy controls were tested by ELISA right before and at the end of 12 weeks of TNFi therapy. The correlation between SICAM- 1 and CXCL13 with disease activity and their predictive values for TNFi response were analyzed

Results: The mean age of the 60 patients were $54.8 \pm 11.6$ years. Serum sICAM-1 and CXCL13 concentration was higher in RA patients than heathy controls, higher in seropositive RA patients than in seronegative ones, and higher in RA patients with higher disease activity (table 1). Serum SICAM-1 and CXCL13 levels were decreased after TNFi therapy, especially in good responders (table 2). Baseline sICAM-1 concentration was independently associated with EULAR response $(\mathrm{p}=0.033, \mathrm{OR}=1.014,95 \% \mathrm{Cl}=1.003-1.026)$. The sICAM$1^{\text {high }} / \mathrm{CXCL} 13^{\text {high }}$ patients had the highest response rate, which was significantly higher than the $\mathrm{sICAM}-1^{\text {low }} / \mathrm{CXCL} 13^{\text {low }}$ group $(\mathrm{OR}=8.143,95 \% \mathrm{Cl}: 1.040-75.482$, $\mathrm{p}=0.045)$.

Table 1. The correlation between serum sICAM-1 and CXCL13 concentrations and disease activity at baseline and 12 weeks after treatment.

\begin{tabular}{|c|c|c|c|c|c|c|c|c|}
\hline & $\begin{array}{c}\text { Baseline } \\
\text { sICAM-1 (ng/ } \\
\text { mL) CXCL13 } \\
\text { (pg/mL) }\end{array}$ & & & & $\begin{array}{c}\text { Week } 12 \\
\text { sICAM-1 (ng/ } \\
\text { mL) CXCL13 } \\
\text { (pg/mL) }\end{array}$ & & & \\
\hline & $r$ & $p$ & $r$ & $p$ & $r$ & $p$ & $r$ & $p$ \\
\hline DAS28-ESR & 0.396 & 0.002 & 0.233 & 0.073 & 0.315 & 0.014 & 0.150 & 0.254 \\
\hline DAS28-CRP & 0.360 & 0.005 & 0.191 & 0.143 & 0.250 & 0.054 & 0.062 & 0.639 \\
\hline SDAI & 0.278 & 0.032 & 0.138 & 0.292 & 0.220 & 0.091 & 0.042 & 0.750 \\
\hline CDAI & 0.277 & 0.032 & 0.116 & 0.377 & 0.182 & 0.163 & 0.009 & 0.943 \\
\hline
\end{tabular}

Table 2. The comparisons of sICAM-1 and CXCL13 concentrations at baseline and 12 weeks based on different response criteria.

\begin{tabular}{|c|c|c|c|c|c|c|c|c|c|c|c|c|}
\hline & $\begin{array}{c}\text { EULAR responder } \\
\text { EULAR non-responder }\end{array}$ & & & & & & $\begin{array}{l}\text { ACR } 20 \text { achieved ACR } \\
20 \text { not achieved }\end{array}$ & & & & & \\
\hline & Baseline & Week 12 & $\mathrm{p}$ & Baseline & Week 12 & $\mathrm{p}$ & Baseline & Week 12 & $\mathrm{p}$ & Baseline & Week 12 & $\mathrm{p}$ \\
\hline $\begin{array}{l}\text { sICAM-1 (ng/ml) } \\
\quad(m e a n \pm S D)\end{array}$ & $388.5 \pm 94.0$ & $325.3 \pm 83.7$ & 0.001 & $302.1 \pm 56.1$ & $334.3 \pm 61.5$ & 0.270 & $390.5 \pm 95.8$ & $329.6 \pm 87.6$ & 0.004 & $345.7 \pm 85.3$ & $329.3 \pm 67.9$ & 0.513 \\
\hline $\begin{array}{l}\mathrm{CXCL} 13(\mathrm{pg} / \mathrm{ml}) \\
\quad(\text { median, min-max) }\end{array}$ & $190.6(50.1-2081.4)$ & $\begin{array}{c}103.3 \\
(4.8-1497.8)\end{array}$ & 0.003 & $\begin{array}{c}120.4 \\
(18.8-1909.4)\end{array}$ & $\begin{array}{c}144.7 \\
(18.4-2155.0)\end{array}$ & 0.546 & $199.7(57.9-2081.4)$ & $\begin{array}{c}103.8 \\
(8.9-2155.0)\end{array}$ & 0.011 & $\begin{array}{c}136.0 \\
(18.8-1909.4)\end{array}$ & $\begin{array}{c}102.2 \\
(4.8-767.33)\end{array}$ & 0.531 \\
\hline
\end{tabular}


Conclusion: sICAM-1 and CXCL13 are elevated in RA patients and correlated with disease activity. SICAM-1 is an independent predictor of TNFi response in csDMARDs refractory RA patients.

References:

[1] Han BK, Kuzin I, Gaughan JP, et al. Baseline CXCL10 and CXCL13 levels are predictive biomarkers for tumor necrosis factor inhibitor therapy in patients with moderate to severe rheumatoid arthritis: a pilot, prospective study. Arthritis Res Ther, 2016, 18: 93.

[2] Greisen SR, Schelde KK, Rasmussen TK,et al. CXCL13 predicts disease activity in early rheumatoid arthritis and could be an indicator of the therapeutic 'window of opportunity'. Arthritis Res Ther, 2014, 16(5): 434.

[3] Klimatcheva E, Pandina T, Reilly C, et al. CXCL13 antibody for the treatment of autoimmune disorders. BMC Immunol, 2015, 16: 6.

Disclosure of Interests: None declared

DOI: 10.1136/annrheumdis-2020-eular.1689

\section{Spondyloarthritis - etiology, pathogenesis and animal models}

\section{AB0113 1 ANTIBODIES AGAINST HELICOBACTER PYLORI ANTIGENS IN PATIENTS WITH PSORIATIC ARTHRITIS AND PSORIASIS}

E. Patrikiou ${ }^{1}$, G. Efthymiou ${ }^{1}$, C. Liaskos ${ }^{1}$, N. Ntavari², E. Zfiriou3,

T. Simopoulou ${ }^{1}$, T. Scheper, ${ }^{4}$, W. Meyer ${ }^{4}$, A. Roussaki-Schulze5, D. Bogdanos ${ }^{1}$.

${ }^{1}$ University of Thessaly, Rheumatology/Clinical Immunology, Larissa, Greece;

${ }^{2}$ University of Thessaly, Dermatology, Larissa, Greece; ${ }^{2}$ University of Thessaly,

Dermatology, Larissa, Greece; ${ }^{4}$ Institute of Experimental Immunology, Affiliated to EUROIMMUN AG, Lubeck, Germany; ${ }^{2}$ University of Thessaly, Dermatology,

Larissa, Greece

Background: Psoriasis (Ps) and Psoriatic Arthritis (PsA) are inflammatory diseases of unknown etiology. Helicobacter pylori $(\mathrm{Hp})$ infection has been hypothesized as one of the microbial agents that can lead to development of immune-mediated psoriatic disease, but the nature of the specific $\mathrm{Hp}$ antigens involved remains unclear.

Objectives: To asses antigen specific antibody responses against immunodominant $\mathrm{Hp}$ antigens in patients with psoriatic diseases.

Methods: Ninety-one patients with Ps (35 females; median age 51.9, age range 25-87), 47 patients with PsA (25 females; median age 52.9, age range 25-87) and 60 demographically matched healthy controls $(\mathrm{HC})$ were studied. Reactivity to Hp-specific antigens were tested by Western immunoblotting (in combination with line immunoassay for anti-CagA and anti-VagA antibody testing) (Euroimmun AG, Lübeck, Germany).

Results: Positivity against $\mathrm{Hp}$ was comparable between PsA (38.3\%), Ps (39.6\%) and HCs (50\%). Anti-p66-UreB, anti-p54-flagelin and anti-p29-UreA abs were more frequent in psoriatic patients compered to healthy controls ( $p 66$ : $94.4 \%$ in Ps vs $69.7 \%$ in $\mathrm{HC}, \mathrm{p}=0.017$; $\mathrm{p} 54: 66.7 \%$ in $\mathrm{Ps}$ vs $33.3 \%$ in $\mathrm{HC}, \mathrm{p}=0.012$; p29 72.2\% in Ps vs $45.5 \%$ in $\mathrm{HC}, \mathrm{p}=0.044)$ and anti-p29-UreA abs were detected in higher frequency in PsA patients compered to $\mathrm{HC}(94.4 \%$ vs $45.5 \%, \mathrm{p}=0.002)$. Reactivities against the remaining $\mathrm{Hp}$ antigens were comparable between Ps and PsA patients and $\mathrm{HC}$.

Conclusion: Antibody responses against p66-UreB, p29-UreA, and p54-flagelin are more prevalent in patients with psoriatic disease, suggesting their potential involvement in PsA and Ps.

Disclosure of Interests: Eleni Patrikiou: None declared, George Efthymiou: None declared, Christos Liaskos: None declared, Niki Ntavari: None declared, Efterpi Zfiriou: None declared, Theodora Simopoulou: None declared, Thomas Scheper, Employee of: Employee of EUROIMMUN AG, Lubeck, Germany, Wolfgang Meyer Employee of: Employee of EUROIMMUN AG, Lubeck, Germany, Aggeliki Roussaki-Schulze: None declared, Dimitrios Bogdanos: None declared DOI: 10.1136/annrheumdis-2020-eular.5383

\section{AB0114 \\ IL12P40/IL23P40 BLOCKADE WITH USTEKINUMAB DECREASES THE INFLAMMATORY INFILTRATE AND MODULATES MOLECULAR PATHWAYS IN THE SYNOVIUM OF PSORIATIC ARTHRITIS PATIENTS}

R. Fiechter ${ }^{1}$, H. De Jong ${ }^{1}$, L. Van Mens ${ }^{1}$, I. Fluri ${ }^{1}$, S. Tas ${ }^{1}$, D. Baeten ${ }^{1}$, N. Yeremenko', M. G. H. Van de Sande ${ }^{1}{ }^{1}$ Amsterdam UMC, Univ of Amsterdam, Rheumatology and Clinical Immunology, Amsterdam, Netherlands

Background: Psoriatic arthritis (PsA) is a chronic inflammatory joint disease within the spondyloarthritis (SpA) spectrum. TNF and IL17/IL23 pathways play a key role in SpA pathogenesis. Blocking of IL12p40/IL23p40 has been shown to effectively reduce disease activity in PsA [1,2]. It is however incompletely understood how IL12p40/IL23p40 blockade affects local inflammatory processes.

Objectives: To investigate the cellular and molecular pathways affected by IL12p40/IL23p40 blockade with ustekinumab in PsA patients (pts)

Methods: Eleven male PsA pts with at least 1 inflamed knee or ankle joint, who were scheduled to start ustekinumab treatment, were included in a 24-week single-center open-label study. All pts received ustekinumab $45 \mathrm{mg} / \mathrm{sc}$ according to standard care at week (W) 0, 4 and 16. Besides clinical outcomes, needle arthroscopic synovial tissue (ST) biopsy samples were obtained from an inflamed knee or ankle joint at baseline (BL), W12 and W24. ST samples were analyzed by immunohistochemistry (IHC), RNA sequencing and real-time quantitative polymerase chain reaction (qPCR) analysis.

Results: Paired BL and W12, and paired BL, W12 and W24 ST samples were available of 9 and 6 pts, respectively. Two pts only underwent BL ST sampling (pt refusal; withdrawal after the W12 clinical visit). Two pts were excluded after W12 because of treatment adjustments. Of 1 pt no ST was obtained at W24 due to technical difficulties. Eight pts finished 24 weeks of clinical follow-up. No serious adverse events were observed. At W12 6/11 pts met ACR20, 2/11 met ACR50 and 1/11 met ACR70 improvement criteria, at W24 this was 3/8, 2/8 and 1/8 pts, respectively. Significant improvements between BL and W12 and/or W24 were seen in clinical (TJC, PASI, BASDAI) and serological markers (CRP and ESR), Table 1. IHC showed a significant decrease in sublining macrophages, a sensitive biomarker of an inflammatory response in peripheral SpA, of $B L 2[1-3]$ vs W12 $1.5[0-2] p=0.020$, but not W24 $1[0.5-2.5] n s$. Other synovial infiltrating cells were not significantly decreased. Significant downregulation of MMP3 $(p=0.047)$ and IL-23p19 $(p=0.046)$, but not IL6, TNF or IL12p40 were seen with qPCR analysis at W12. RNA seq analysis showed 178 significantly differentially expressed genes between BL and W12 (FDR 0.1). Gene ontology and KEGG terms enrichment analyses identified overrepresentation of MAPK and PI3K-Akt signalling pathways among the down-regulated genes and WNT signalling pathway among the up-regulated genes. Gene expression was confirmed by qPCR analysis.

Table 1.

\begin{tabular}{lccccc}
\hline & $\begin{array}{c}\text { Baseline } \\
(\mathrm{n}=11)\end{array}$ & $\begin{array}{c}\text { Week 12 } \\
(\mathrm{n}=11)\end{array}$ & $\begin{array}{c}\text { Week 24 } \\
(\mathrm{n}=8)\end{array}$ & $\mathrm{p}$-value* & p-value** \\
\hline TJC & $1(0-5)$ & $1(1-2)$ & $0(0-0.75)$ & 0.168 & 0.034 \\
SJC & $2(1-3)$ & $2(1-3)$ & $1.5(1-2)$ & 0.394 & 0.715 \\
VAS patient global & $28(16-55)$ & $22(12-46)$ & $45(2.8-50.5)$ & 0.423 & 0.779 \\
PASI & $3.2(1.2-7.4)$ & $0.8(0-1.8)$ & $0(0-2.4)$ & 0.028 & 0.046 \\
BASDAI & $3.2(2.4-4.7)$ & $1.9(1-3.8)$ & $2.1(0.4-4.2)$ & 0.008 & 0.161 \\
CRP (mg/L) & $8.5(1.7-16.4)$ & $1.6(0.6-3)$ & $1.0(0.6-7.0)$ & 0.008 & 0.012 \\
ESR (mm/hr) & $20(8-35)$ & $6(2-17)$ & $8(2-20.5)$ & 0.008 & 0.017 \\
\hline
\end{tabular}

TJC/SJC tender/swollen joint count; VAS visual analogue scale; PASI psoriasis area severity index; BASDAI Bath Ankylosing Spondylitis Disease Activity Index; CRP C-reactive protein; ESR erythrocyte sedimentation rate;

All values are presented as median (IQR) p-value for the comparison of baseline and week $12\left(^{*}\right)$ or week $24\left({ }^{* *}\right)$

Conclusion: Ustekinumab treatment reduced synovial inflammation and modulated specific molecular pathways, however inflammation was not completely resolved. Future studies comparing histological and gene expression data between different treatments targeting IL17/IL23 axis will show which changes are treatment-specific and which reflect downregulation of local inflammation. References:

[1] Mclnnes et al. Lancet. 2013;382:780-789.

[2] Kavanaugh et al. Ann Rheum Dis. 2014;73:990-999.

Work was financially supported by an unrestricted grand of Janssen Pharmaceutica

Disclosure of Interests: Renée Fiechter: None declared, Henriëtte de Jong: None declared, Leonieke van Mens: None declared, Inka Fluri: None declared, Sander Tas: None declared, Dominique Baeten Employee of: UCB Pharma, Nataliya Yeremenko: None declared, Marleen G.H. van de Sande Grant/research support from: Novartis, Eli lily, UCB, Jansen, Consultant of: Abbvie, Novartis, Eli lily, MSD DOI: 10.1136/annrheumdis-2020-eular.4518

\section{AB0115 NEUTROPHIL HOST DEFENCE IN PSORIATIC ARTHRITIS}

A. Cross $^{1}$, J. Hawkes ${ }^{1}$, H. Frankland ${ }^{2}$, A. Mediana ${ }^{2}$, H. Wright ${ }^{1}$, N. Goodson ${ }^{1,2}$ S. Edwards ${ }^{3}$, R. Moots ${ }^{1,2}{ }^{1}{ }^{1}$ University of Liverpool, Institute of Ageing and Chronic Disease, Liverpool, United Kingdom; ${ }^{2}$ Liverpool University Hospitals NHS Foundation Trust, Rheumatology, Liverpool, United Kingdom; ${ }^{3}$ University of Liverpool, Institute of Integrative Biology, Liverpool, United Kingdom 